\title{
Study on Extraction Technology of Polysaccharides from Jujube by Microwave Method
}

\author{
Minghang Xu, Xinjian Yao, Jun Wang* \\ Department of Chemistry, Zhoukou Normal University, ZhouKou, China \\ Email: *zk-wangjun@163.com
}

How to cite this paper: Xu, M.H., Yao, X.J. and Wang, J. (2017) Study on Extraction Technology of Polysaccharides from Jujube by Microwave Method. Open Access Library Journal, 4: e3470.

https://doi.org/10.4236/oalib.1103470

Received: February 19, 2017

Accepted: March 6, 2017

Published: March 9, 2017

Copyright (C) 2017 by authors and Open Access Library Inc.

This work is licensed under the Creative Commons Attribution International License (CC BY 4.0).

http://creativecommons.org/licenses/by/4.0/ (c) (i) Open Access

\begin{abstract}
Jujube polysaccharide is one of the important natural active ingredients. In this paper, microwave extraction technology was utilized to extract jujube polysaccharide in different conditions using the yield as test index. The results showed that the optimum conditions were solid-liquid ratio $1: 30$, ultrasonic lasting time $25 \mathrm{~min}$, temperature $50^{\circ} \mathrm{C}$, which achieve the highest yield rate $5.38 \%$.
\end{abstract}

\section{Subject Areas}

Analytical Chemistry

\section{Keywords}

Microwave Extraction, Polysaccharides, Jujube

\section{Introduction}

Ziziphus jujube, the fruits of rhamnales, is one of Chinese traditional health foods, which has been applied in curing deficiency of qi and weakness of the spleen as a Chinese medicine for about 2000 years [1]. It has been found in recent pharmacological studies that a variety of natural bioactive substances are contained in jujube, such as polysaccharides, flavonoids and dietary fiber [2] [3] [4]. Polysaccharides are composed of a number of monosaccharides joined by glycosidic bonds, which have medical effects of the immunoregulatory, lowering blood lipids and antitumor. The main extraction methods of polysaccharides from jujube in recent reports are hot water bath extraction, organic solvent extraction and sour alkali soak extraction, while these methods have some disadvantages like long extraction time, low extraction efficiency and high impurity content. 
The principle of microwave assisted extraction is to let rays penetrate the cell wall to reach the cell interior under microwave, making temperature rise and pressure increase, thus the cell wall would be broken, at the same time, the effective components inside of the cell are released and transferred into the solution [5] [6]. In this paper, microwave extraction technology was utilized to extract jujube polysaccharides.

\section{Experimental}

\subsection{Materials and Methods}

\subsubsection{Materials}

Chinese jujube were bought in the local area, after cleaned and dried to constant weight at $50^{\circ} \mathrm{C}$, they were ground to the particle size 60 mesh. Glucose, sulfuric acid and phenol were purchased from Chemical Reagent Co. Ltd. (Tianjin, China). All the solvent used are analytical reagent.

Instruments: high speed disintegrator, Midea M1-L202B microwave oven and 751 UV spectrophotometer.

\subsubsection{Determination of the Drawing of Standard Curve}

$10.0 \mathrm{mg}$ glucose was dissolved in distilled water, then transferred into a $250 \mathrm{~mL}$ volumetric flask to calibrate, shaked up and placed still. Afterwards 0.0, 0.2.0, $0.4,0.6,0.8,1.0$, and $1.2 \mathrm{~mL}$ glucose standard solution were sucked up respectively to different $2 \mathrm{~mL}$ comparison tubes, then added $1.0 \mathrm{~mL} 6 \%$ phenol solution and $5.0 \mathrm{~mL}$ sulfuric acid to each test tube. Used distilled water as a reference to measure its absorbance at $490 \mathrm{~nm}$, thus obtained the standard curve under different concentrations. The equation between Absorbance $(\mathrm{Y})$ and concentration of glucose $(\mathrm{X})$ in the scope of measurement was: $\mathrm{Y}=7.81868 \mathrm{X}+0.10226, \mathrm{R}^{2}=$ 0.9980 (Figure 1).

\subsubsection{Calculation of Polysaccharide Yield}

Polysaccharide extraction yield $(\%)=$ determined polysaccharide mass/raw material mass $\times 100 \%$.

\section{Results and Discussion}

The extraction yield of polysaccharide is mainly influenced by extraction temper-

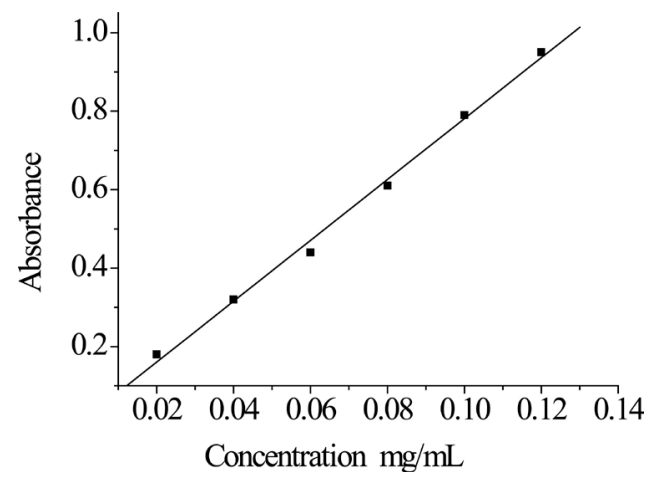

Figure 1. Standard curves of glucose solution. 
ature, time and weight ratio of liquid/solid. In order to control the extraction temperature exactly, we maintain microwave power at $300 \mathrm{~W}$, the three factors above are investigated to study effect on the extraction yield.

\subsection{Effect of Temperature on Extraction Yield}

Temperature is an important factor of extraction yield. It is shown that the different yield of polysaccharide from jujube at different temperature in Figure 2. High temperature would increase the solubility of polysaccharide from jujube, as is seen in the temperature scope from $20^{\circ} \mathrm{C}$ to $50^{\circ} \mathrm{C}$. But higher temperature beyond $50^{\circ} \mathrm{C}$ will cause degradation of polysaccharide.

\subsection{Effect of Radiation Time on the Extraction Yield}

Microwave radiation time is another important factor influenced the yield of polysaccharide. The results show in Figure 3 that under microwave radiation, the yield is increasing among $10-25$ min and reach the maximum 5.3\%, afterwards it falls. It illustrates that the structure of polysaccharide could be changed and the sugar chain be broken, so that overlong radiation time would also cause degradation of polysaccharide.

\subsection{Effect of Weight Ratio of Solid/Liquid on the Extraction Yield}

We can clearly know from Figure 4 that the ration of solid/ liquid is obviously

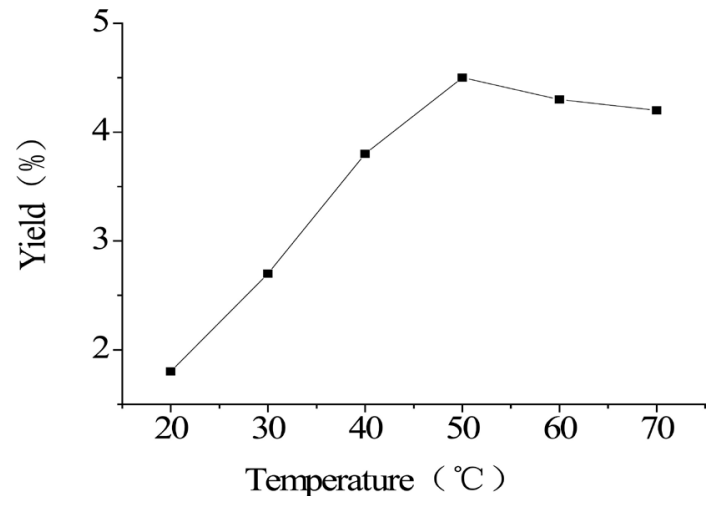

Figure 2. Effect of temperature on the extraction yield.

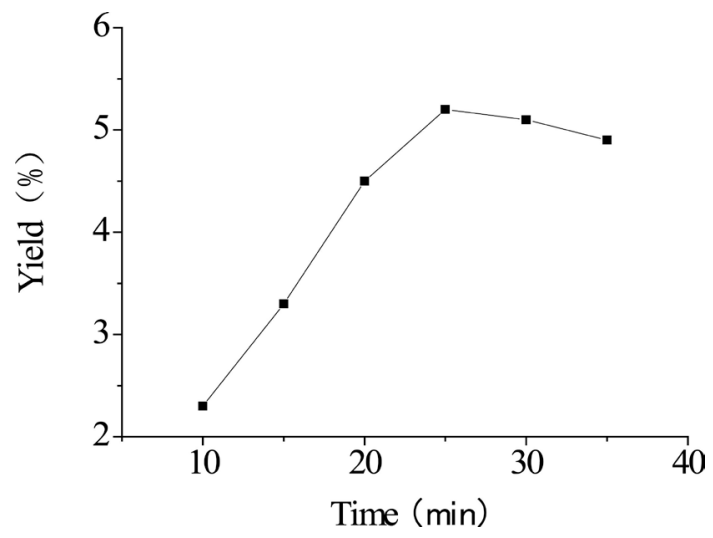

Figure 3. Effect of time on the extraction yield. 


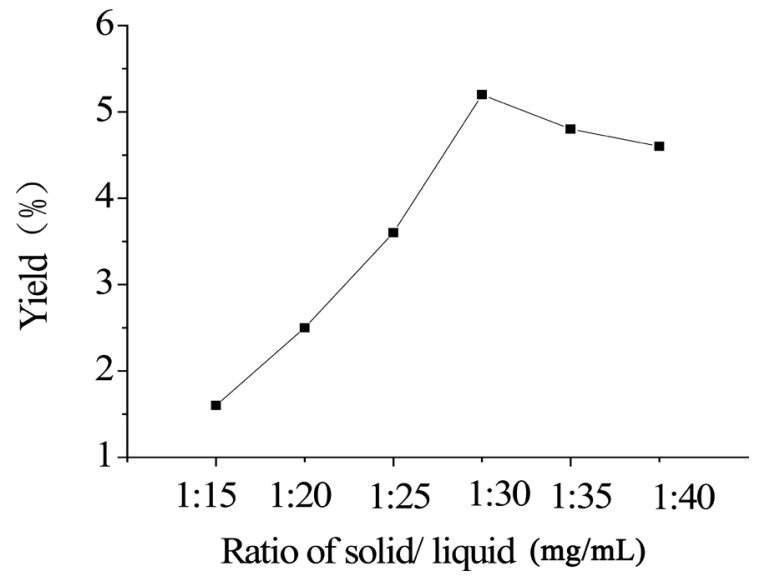

Figure 4. Effect of weight ratio of liquid/solid on the extraction yield.

influenced the yield, the yield is increasing in accordance with the augment of ration of solid/liquid, considering the cost and difficulty of separation, the ratio 1:30 is preferred.

\section{Conclusion}

In this study, it was investigated the extraction of polysaccharide from jujube based on single-factor tests using microwave radiation method. We obtain the optimization condition at $300 \mathrm{~W}$ power, extraction time $25 \mathrm{~min}$, temperature $50^{\circ} \mathrm{C}$, weight ratio of solid/liquid 1:30. The extraction process has some advantages like mild condition, short time and easy post-process, which provides a technical possibility for local jujube's deep processing.

\section{Acknowledgements}

This study is supported by the opening of laboratory program for Department of Chemistry and Chemical Engineering, Zhoukou Normal University (No. HXK201604) and Zhoukou Normal University School-Based Project (No. ZKNUB2201701).

\section{References}

[1] Li, S.Z. (1982) Compendium of Materia Medica. People's Medical Publishing House, Beijing, 1754-1760.

[2] Wang, J. and Zhang, B.S. (2003) Study on Nutritional Components and Functions of Chinese Jujube. Food Research and Development, 24, 68-72.

[3] Zhang, Z., Gao, Z.M. and Qian, R.S. (2006) Study on Physical and Chemical Property of Jujube Polysaccharides and It's Extration. Storage and Process, 6, 30-32.

[4] Tadashi, K. (1997) Polysaccharrides in Fungi XXXVIII Antidiabetic Activity and Structural Feature of Agalactmannan Elaborated by Pestalotiopsis Species. Biological and Pharmaceutical Bulletin, 20, 118-121. https://doi.org/10.1248/bpb.20.118

[5] Yin, T.-Z., Xiong, G.-X., Wang, N., et al. (2016) Study on Extraction of Polysaccharide from Red Date by Multiple Enzymatic Assisted Microwave. Hubei Agricultural Sciences, 55, 1799-1801.

[6] Niu, X.Y. and Xu, Q. (2011) Study on Microwave Assisted Extraction of Jujube Polysaccharide. Guangxi Journal of Light Industry, 149, 74-75. 
Submit or recommend next manuscript to OALib Journal and we will provide best service for you:

- Publication frequency: Monthly

- 9 subject areas of science, technology and medicine

- Fair and rigorous peer-review system

- Fast publication process

- Article promotion in various social networking sites (LinkedIn, Facebook, Twitter, etc.)

- Maximum dissemination of your research work

Submit Your Paper Online: Click Here to Submit

Or Contact service@oalib.com 